DOI 10. 18307/2021. 0501

(C) 2021 by Journal of Lake Sciences

\title{
鄱阳湖长江江豚的现状和保护展望
}

梅志刚 ${ }^{1,2}$, 郝玉江 ${ }^{1,2}$, 郑劲松 ${ }^{1,2}$, 王志陶 ${ }^{1,2}$, 王克雄 ${ }^{1,2 * *}$, 王 $丁^{1,2 * *}$ (1: 中国科学院水生生物研究所, 中国科学院水生生物多样性与保护重点实验室,武汉 430072)

(2: 国家水生生物种质资源库,武汉 430072)

\begin{abstract}
摘 要: 长江江豚 (Neophocaena asiaeorientalis asiaeorientalis) 是一种小型齿鲸, 仅分布在长江中下游干流和洞庭湖及鄱阳 湖中, 其种群数量仅约 1000 头, 极度濒危. 鄱阳湖是长江江豚最重要的栖息地之一, 估算种群数量约 450 头, 是长江江豚 最后的避难所. 本文系统地总结了鄱阳湖长江江豚种群生态学、保护遗传学和保护生物学的研究进展, 着重探讨了各种 人类活动对其种群迁移活动的影响, 并对鄱阳湖长江江豚种群面临的威胁、保护对策和未来研究方向等进行了总结和展 望, 以期为今后的保护工作提供借鉴.
\end{abstract}

关键词: 鄱阳湖; 长江江豚; 保护生物学; 保护对策

\section{Population status and conservation outlooks of Yangtze finless porpoise in the Lake Poy- ang*}

Mei Zhigang ${ }^{1,2}$, Hao Yujiang ${ }^{1,2}$, Zheng Jinsong ${ }^{1,2}$, Wang Zhitao ${ }^{1,2}$, Wang Kexiong ${ }^{1,2 * *} \&$ Wang Ding ${ }^{1,2 * *}$

(1: Key Laboratory of Aquatic Biodiversity and Conservation of the Chinese Academy of Sciences, Institute of Hydrobiology, Chinese Academy of Sciences, Wuhan 430072, P.R.China)

(2: National Aquatic Biological Resource Center, Wuhan 430072, P.R.China)

\begin{abstract}
Yangtze finless porpoise (Neophocaena asiaeorientalis asiaeorientalis) is now likely the sole cetacean in the Yangtze River, which is only distributed in the middle and lower reaches of the Yangtze River mainstem, Lake Dongting and Lake Poyang. The population size is only about 1000 and critically endangered. As the most critical habitat of Yangtze finless porpoise, Lake Poyang is the last refuge of Yangtze finless porpoise with an estimated population size of about 450. This paper is a systematic summary of the research progress on the population ecology, conservation genetic and conservation biology of the Yangtze finless porpoise population in the Lake Poyang, with emphasis on the influence of various human activities on its population migration activities, and concluding remarks and outlook on the threats to Yangtze finless porpoise population in Lake Poyang, conservation measures and future research directions, aiming to provide a reference for the related conservation.
\end{abstract}

Keywords: Lake Poyang; Yangtze finless porpoise; conservation biology; conservation measures

江豚属 (Neophocaena) 是隶属于鲸目 (Cetacea)、齿鲸亚目 (Odontoceti)、鼠海豚科( Phocoenidae) 的一种 小型齿鲸类动物, 其分布范围西至波斯湾, 东至日本海, 南至巴基斯坦、印度、印尼、婆罗洲和中国 ${ }^{[1]}$. 江豚属 的分类一直受到争议, 早期通过对江豚标本外形测量指标进行比较分析, 认为江豚应该分为 3 个亚种 ${ }^{[2-3]}$, 随后 Jefferson 等 $^{[4]}$ 根据江豚背部形态测量、头骨形态测量、江豚体色以及分子遗传学证据将江豚分为印度 太平洋江豚 (Neophocaena phocaenoides) 和窄脊江豚 (Neophocaena asiaeorientalis), 其中窄脊江豚又分为长江 江豚 (N. a. asiaeorientalis) 和东亚江豚 (N. a. sunameri) 两个亚种. 近年, 基于基因组的研究显示, 长江江豚或 可能是独立的物种 ${ }^{[5]}$, 是唯一而且相对独立的一个江豚淡水种群 ${ }^{[6]}$, 也是鼠海豚科所有物种中唯一的淡水 种群, 仅分布于长江中下游干流及洞庭湖和鄱阳湖中, 是中国水域 3 个江豚种群中最濒危的 1 个亚种. 长江

* 2021-06-10 收稿;2021-07-07 收修改稿. 江西省水利科技计划重点项目 (201922ZDKT01) 资助.

** 通信作者;E-mail: wangk@ihb.ac.cn,wangd@ihb.ac.cn. 
江豚 1996 年被国际自然保护联盟列为濒危物种, 2013 年起被列为极度濒危物种 ${ }^{[7]}$. 在 2021 年新修订的《国 家重点保护野生动物名录》中, 长江江豚被调整为国家一级保护野生动物.

随着人类对长江的开发力度不断加大, 长江江豚的种群数量从上世纪末开始快速减少. 1990s 初期, 长 江江豚的种群数量估算约为 2700 头 ${ }^{[8]}$, 到 2006 年其种群数量已经下降到约 1800 头, 长江干流种群年下降 速率超过 5\% ${ }^{[9]} .2012$ 年考察显示种群数量已经下降至约 1040 头, 与 2006 年相比, 长江干流种群年下降速 率达到 $13.73 \%$, 面临极高的灭绝风险 ${ }^{[10-11]}$. 长江江豚极度濒危的现状引起了政府主管部门和社会的普遍关 注, 农业农村部 (原农业部) 启动了拯救行动计划, 力争在 5 年内遏制种群的快速衰退. 2017 年长江江豚生 态科学考察结果显示种群数量约 1012 头; 其中长江干流约 445 头, 与 2012 年相比, 无显著差别, 种群快速衰 退的趋势得到基本遏制, 但其极度濒危的现状没有改变 ${ }^{[12]}$. 作为长江淡水生态系统健康的指示物种和长江 生物多样性的重要标志, 加强对长江江豚的保护迫在眉睫 ${ }^{[13]}$.

鄱阳湖 $\left(28^{\circ} 11^{\prime} \sim 29^{\circ} 51^{\prime} \mathrm{N}, 115^{\circ} 31^{\prime} \sim 117^{\circ} 06^{\prime} \mathrm{E}\right)$ 是中国当前第一大淡水湖, 位于江西省北部, 长江中下游 南岸, 也是目前仅有的 3 个自然通江湖泊之一. 与长江干流相比, 历史上鄱阳湖地区工业化水平较低, 周围 的居民主要以渔业捕捞为生 ${ }^{[14]}$, 拥有优越的自然条件和丰富的水资源及鱼类资源, 是长江江豚较为理想的 栖息地. 它承纳赣江、抚河、信江、饶河、修水等五大河流的来水, 经调蓄后由湖口注人长江, 是一个过水型、 吞吐型、季节型的湖泊,高水湖相, 低水河相 (图 1), 具有 “洪水一片, 枯水一线”的独特景观 ${ }^{[14-15]}$.
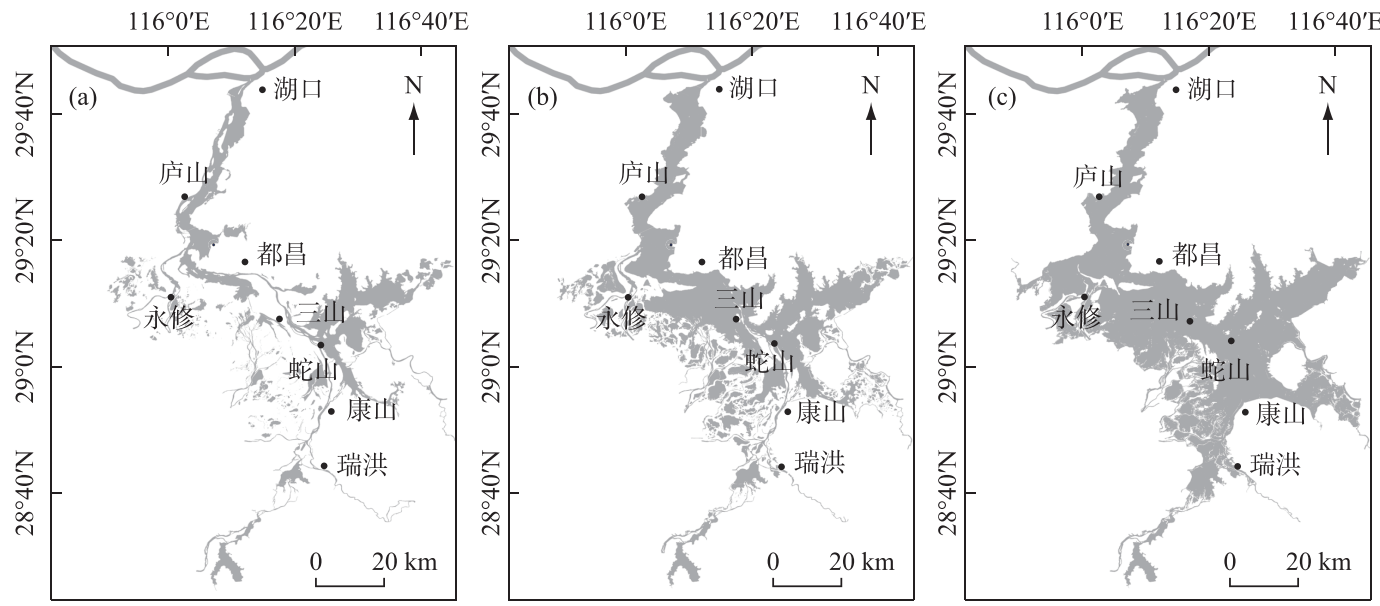

图 1 不同水文时期鄱阳湖水域面积 $(\mathrm{a}$ : 低水位; $\mathrm{b}$ :中水位; $\mathrm{c}$ :高水位)

Fig. 1 The water area of Lake Poyang in different hydrological periods (a: low water level; b: medium water level; c: high water level)

中国古代关于江豚的记载最早出现于东汉许慎所著的《说文解字》: “䱡, 鱼名, 出乐浪潘国。从鱼, 掬 声. 一曰䱊鱼, 出江东, 有两乳.” “江东” 大约包括今天的江西东北部、皖南、苏南、上海、浙江等, 大致意思是: 江豚出产于朝鲜沿海和长江流域鄱阳湖至上海一带. 由此可见国人最早认识长江江豚是从鄱阳湖开始的. 根据历年来长江江豚种群调查的结果, 几乎一半的长江江豚栖息在鄱阳湖 ${ }^{[12]}$. 因此, 对鄱阳湖长江江豚种 群进行有效保护是整个长江江豚保护的关键. 本文系统地总结了关于鄱阳湖长江江豚种群的研究进展, 分 析了当前存在的主要威胁,展望了未来研究方向,尝试提出了相关的保护建议.

\section{1 鄱阳湖长江江豚的种群动态及分布}

早期研究人员主要关注长江干流江豚的种群数量, 专门针对鄱阳湖的种群调查开展较少. 1997 年 11 月-1998 年 11 月首次开展了鄱阳湖长江江豚的完整调查, 结果表明, 鄱阳湖长江江豚的种群数量估算为 100 400 头, 种群数量随季节、水位、鱼类资源的变化而呈现出相应的变化 ${ }^{[16]}$. 进人 21 世纪后, 中国科学院 水生生物研究所对鄱阳湖长江江豚种群开展了系统的调查. 结果显示, 2005-2007 年, 丰水期鄱阳湖长江江 
豚种群数量约为 487 头 (变异系数 $C_{\mathrm{V}}=0.176,95 \%$ 置信区间 $C I=256 \sim 932$ ), 密度为 0.780 头 $/ \mathrm{km}^{2}\left(C_{\mathrm{V}}=\right.$ $0.176,95 \% C I=0.552 \sim 1.102)$; 枯水期长江江豚种群数量为 484 头 $\left(C_{\mathrm{V}}=0.119,95 \% C I=248 \sim 657\right)$, 密度为 3.113 头 $/ \mathrm{km}^{2}\left(C_{\mathrm{V}}=0.119,95 \% C I=2.466 \sim 3.930\right)^{[17]} .2012$ 和 2017 年估算鄱阳湖长江江豚的种群数量分别为 450 头 $\left(C_{\mathrm{V}}=0.7426,95 \% C I=51 \sim 3432\right)^{[18]}$ 和 457 头 $\left(C_{\mathrm{V}}=0.1683,95 \% C I=329 \sim 634\right)^{[12]}$, 期间种群数量保持 相对稳定,约占到目前整个现存种群的二分之一.

$2005-2017$ 年,鄱阳湖枯水期长江江豚的考察 目击率总体呈现波动稳定状态, 不同年份的差别主 要是由水位不同造成的 (图 2) ${ }^{[12]} .2008-2012$ 年, 沿着主航道对鄱阳湖水域 (130 km) 进行了被动声 学考察, 结果显示鄱阳湖主航道的长江江豚检测密 度会随着水位的不同产生变化, 但不同年份之间没 有差别 ${ }^{[19]} .2018$ 和 2019 年枯水期, 中国科学院水生 生物研究所持续对鄱阳湖及其主要支流中长江江豚 的种群数量进行了调查, 目击率与 2017 年相比没有 显著性差别 (均为 1000 头次左右), 这也显示鄱阳湖 种群数量维持较为稳定.

历次考察结果均显示鄱阳湖湖区及其主要支流 (赣江、信江、抚河、饶河) 的尾问水域都有长江江豚 分布 ${ }^{[18]}$, 不同季节长江江豚的分布地点不尽相

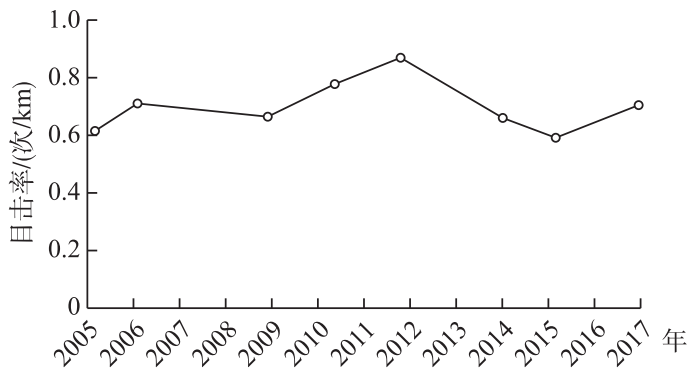

图 2 2006-2017 年枯水期鄱阳湖 长江江豚考察目击率 ${ }^{[12]}$

Fig. 2 Encounter rates of Yangtze finless porpoises during low-water seasons in Lake Poyang (2006-2017) ${ }^{[12]}$

同 ${ }^{[16]}$, 其分布范围、数量和活动规律随着水位变化而变化 ${ }^{[20-21]}$. 食物资源或 (和) 水文特征变化可能是引起 长江江豚分布的重要原因 ${ }^{[22]}$. 随着水深的增加, 长江江豚的分布密度逐步递减, 呈现典型的指数分布模 式 ${ }^{[23]}$. 在湖口至八里江水域小型鱼类聚集的水域发现长江江豚的概率大于 $70 \%{ }^{[24]}$. 总体来看, 枯水期在整 个鄱阳湖湖区和主要支流尾问的适宜水深范围内均有长江江豚分布. 星子水域、老爷庙至小矶山水域、龙口 水域及余干县康山水域为长江江豚高密度分布区; 尤其在采砂遗留的大型沙坑水域, 长江江豚分布密集 ( 这 些水域是鄱阳湖枯水期主要的开阔水面). 丰水期, 长江江豚在全湖呈现扩散分布 ${ }^{[18]}$. 此外, 随着主湖区的 人类干扰愈发频繁, 长江江豚种群在枯水季节呈现更显著向支流内分布的趋势 ${ }^{[21]}$.

\section{2 鄱阳湖长江江豚的栖息地选择}

长江江豚经常出现在支流湖泊与长江的汇合处、弯曲河段以及江心洲头尾. 这些水域坡度较缓, 流速较 慢, 有机物质沉降丰富, 底质为淤泥, 沿岸植物茂盛, 浮游生物量较大, 常见大群小型鱼类, 是长江江豚的重 要栖息地 ${ }^{[8,23,25]}$. 在湖口八里江水域长江江豚的出现与鱼类资源呈现显著正相关,而与船只的出现没有显著 相关性. 此外, 研究也显示长江干流江豚会冒着风险在码头区捕食, 其分布主要受到食物因素的驱动 ${ }^{[24,26-27]}$. 连续的种群调查显示约 $80 \%$ 以上的个体分布在近岸 $300 \mathrm{~m}$ 以内水域, 而离岸 $500 \mathrm{~m}$ 以外活动较少 ${ }^{[22]}$, 其在 长江干流的分布与自然岸线特征存在高度相关性 ${ }^{[28-29]}$.

在鄱阳湖水域,枯水期长江江豚的目击率与货船密度呈显著负相关关系 ${ }^{[30]}$. 在任何水文时期, 水深都 是影响长江江豚栖息地选择的重要环境因子, 适宜水深范围为: 低水位时期 4 8 m, 中水位时期 $6 \sim 12 \mathrm{~m}$, 高 水位时期 7 20 $\mathrm{m}^{[21]}$. 中低水位时期, 水深、坡度和最冷季降水量是影响长江江豚分布的最重要因子, 这 3 个 因子的平均累计贡献率达到 $78.5 \%$; 高水位时期,最冷季降雨量、最干季降雨量和水深是影响长江江豚分布 的最重要因子,这 3 个因子的平均累计贡献率达到 $74.35 \%$. 长江江豚适宜栖息地面积随水文季节变化而变 化,即高水位时期最大 $(16.89 \%)$, 低水位时期最小 $(12.11 \%)$, 但所占总湖区比例都较低 ${ }^{[21]}$.

在长江干流, 哺乳期的母子豚常出现在水深较浅、流速较缓的水域, 有时甚至观察到长江江豚在深度小 于 $1 \mathrm{~m}$ 的水域进行哺乳 ${ }^{[31]}$. Chen 等 ${ }^{[32]}$ 对鄱阳湖都昌水域栖息的长江江豚种群进行了亲缘关系分析, 发现 母子对基本都在沙坑水域被捕获, 而成年的雄性长江江豚主要是在河道水域被捕捞, 推测鄱阳湖沙坑水域 是枯水期长江江豚主要的抚幼栖息地. 


\section{3 鄱阳湖长江江豚的迁移行为}

\section{1 长江江豚的江湖迁移行为}

鄱阳湖是长江中下游仅有的 3 个通江湖泊之一, 也是当前可能仅有呈现长江江豚江湖迁移行为的水 域,其江湖迁移行为受种群数量下降、水文情势变化和人类活动等因素的影响, 呈现显著减少 ${ }^{[10]}$.

1989 和 1993 年枯水期, 张先锋等 ${ }^{[8]}$ 发现在鄱阳湖湖口水域长江江豚的种群数量存在季节性变化, 一般 冬季( $11-12$ 月) 明显高于春季( $3-4$ 月). 在该水域还观察到了长江江豚在江湖之间的大规模迁移,包括 季节性迁移和日迁移. 据此推断不同季节长江江豚种群数量的差异可能是由种群迁移所致, 并进一步推测 长江江豚有可能在长江中下游干流和鄱阳湖之间存在大规模、长距离的迁移行为 ${ }^{[8]}$.

1997-1998 年, 通过系统的调查, 肖文等 ${ }^{[16]}$ 对冬、春、秋 3 个季节鄱阳湖水系长江江豚种群数量的估计 值分别为 91 、431 和 260 头, 不同季节种群数量的剧烈波动显示鄱阳湖长江江豚可能存在较大规模的江湖 迁移行为, 迁移趋势大致可以归纳为: 春夏季节, 长江江豚由江人湖; 秋冬季节, 由湖人江. 2000 年后随着长 江江豚种群数量持续下降及湖口水域人类活动强度增加, 枯水期江湖迁移行为逐步减少, 湖口水域大规模 的江湖迁移行为已无法观察到 ${ }^{[33]} .2004$ 年后, 湖口水域的鄱阳湖公路大桥和铜九铁路大桥相继建成, 进一 步对长江江豚江湖迁移造成干扰. 在鄱阳湖公路桥和铁路桥之间水域长江江豚分布密度较低, 目视观察已 经较少发现长江江豚的江湖迁移行为 ${ }^{[34-35]}$.

2007 年 11 月- 2008 年 10 月, 定点声学监测结果显示, 丰水期比枯水期有更多长江江豚在铁路桥和公 路桥之间水域活动, 并且能长时间在此停留. 动物在枯水季节下行数量 (鄱阳湖至长江) 多于上行数量 (长江 至鄱阳湖), 而在丰水季节却相反. 因此推测, 长江江豚可能仍存在一定规模的季节性江湖迁移行为, 迁移节 律大致与肖文等观察的结果一致 ${ }^{[16,35]}$.

2008-2010 年, Kimura 等 ${ }^{[24]}$ 在鄱阳湖湖口和干流八里江水域共进行了 9 次流动的被动声学考察, 结果 显示长江江豚分布于整个考察水域, 并且有显著的季节分布模式. 可以粗略地分为两个时期: $5-8$ 月 (春夏 丰水期), 在湖口至蛤蟆石水域 (湖区水域) 只发现较少的长江江豚, 大量的动物聚集在鄱阳湖与长江的交汇 区, 显示此时长江江豚主要是想要从长江干流迁人鄱阳湖; 11 月至次年 2 月 (秋冬枯水期), 在湖口至蛤蟆石 水域, 尤其是铜九铁路大桥以上区域发现更多的动物, 江湖交汇区分布较少, 显示此时长江江豚主要是想要 从鄱阳湖迁人长江干流. 这与之前研究报道的长江江豚江湖迁移节律较为一致.

2011-2020 年,中国科学院水生生物研究所在鄱阳湖铁路大桥和公路大桥之间水域持续开展了定点被 动声学监测, 结果显示不同季节两桥之间能够监测到长江江豚声信号, 显示可能存在江湖迁移行为.

总体来看, 目视观察和被动声学监测都在鄱阳湖铁路大桥和公路大桥之间水域发现长江江豚或者探测 到长江江豚的声信号, 说明当前长江江豚仍然可能通过该水域进行迁移. 长江江豚是哺乳动物, 在封闭的迁 地保护区内亦可以完成整个生活史过程, 不存在由于繁殖等需求驱动的迁移. 因此推测, 鄱阳湖与长江干流 之间的江湖迁移行为主要由捕食需求和/或空间需求驱动.

由于目视观察时间有限和定点被动声学监测站数量不足, 目前的研究结果并不能肯定说明长江江豚的 江湖迁移格局和规模. 但是目视观察和被动声学监测到这一水域的长江江豚的数量都较少, 显示当前长江 江豚江湖迁移规模不大 ${ }^{[10]}$. 遗传学分析也显示长江江豚过去存在大规模的江一湖基因交流, 而现在, 个体和 基因交流明显减少 ${ }^{[36]}$.

\section{2 长江江豚在鄱阳湖主湖区及支流的迁移行为}

目前关于长江江豚的迁移行为研究主要集中于鄱阳湖湖口水域与长江八里江江段之间, 对于长江江豚 在主湖区和支流之间的迁移行为研究较少. 鉴于当前长江江豚的江湖迁移规模不大, 不同季节鄱阳湖长江 江豚种群观测数量的巨大差异, 提示动物在不同季节可能存在主湖区和主要支流间的移动行为 ${ }^{[17]}$. 推测其 移动方向为枯水期由湖人河, 而丰水期由河人湖 ${ }^{[22]} .2018$ 年 6 月在鄱阳湖水域开展了长江江豚无线电跟踪 实验, 对 2 头长江江豚实施了 16 天跟踪, 结果显示随着水位的上涨, 长江江豚从释放的瑞洪镇下游支流河道 向鄱阳湖主湖区进行移动, 移动趋势与之前的预测结果一致.

2018 年 10 月- 2020 年 8 月,在信江、抚河和赣江南支交汇处(康山河段) 至都昌县的主湖区水域(约 70 
$\mathrm{km}$ ) 开展了逐月的长江江豚种群监测 (图 1), 结果显示在鄱阳湖湖区及支流水域长江江豚分布呈明显的季 节性变化, 低水位时期目击频次最多, 在康山河段和湖区主航道呈连续分布. 高水位时期康山河段目击频次 最少,长江江豚在主湖区扩散分布. 不同季节长江江豚的核心栖息地分布有所不同,中低水位时期,其 $50 \%$ 核心栖息地为三山水域、龙口水域、康山至三江口水域; 高水位时期,其 $50 \%$ 核心栖息地为都昌县附近水域 和三山附近水域 (湖区水域). 长江江豚在鄱阳湖湖区和主要支流间存在季节性的迁移活动, 且迁移行为与 水位波动有良好的时间一致性,其移动方向在枯水期由湖区进人支流, 而在丰水期由支流进人湖区 ${ }^{[21]}$.

\section{4 鄱阳湖长江江豚的社群结构}

2009、2010 和 2011 年, 中国科学院水生生物研究所在鄱阳湖都昌水域开展了连续 3 年的捕豚科研活 动, 共捕获长江江豚 93 头. 应用 Siler's Model 建立了生命表, 结果显示鄱阳湖长江江豚的种群呈现下降的趋 势, 下降速率为 $3.5 \%$ / a. 在捕获的 93 头长江江豚中, 雌雄性比为 $44: 49$, 接近 $1: 1^{[18]}$. 一共捕获到成年雌性 江豚 27 头, B 超检测, 确认其中 19 头怀孕, 妊娠率为 $70.4 \% .2009$ 年捕获的一头怀孕长江江豚在 2011 年被 重捕, 再次怀孕, 表明野外性成熟的雌性长江江豚可以间隔一年妊娠 ${ }^{[36]}$.

3 年一共捕获 21 对母子豚, 16 对是同一批捕起, 其中雌性后代年龄为 $0.1 \sim 9.5$ 岁不等 (10 头), 雄性后 代均小于 2 岁 (6头). 所有父子对均不是同一批捕起, 说明雄性可能不参与抚幼. 湖区长江江豚最稳定的集 群单元可能是母子对, 母子对有可能单独活动或者生活在大群体中, 大群体的社会结构有典型的母系社会 特征, 即䧳性后代留在出生群体中, 而雄性后代约 2 岁左右扩散出去, 扩散出去的雄性长江江豚的分布具有 随机性 ${ }^{[36]}$. 研究还发现, 长江江豚为混交制, 雌性个体约 4.5 岁就能成功生育后代, 且生殖年限在 10 年 以上.

\section{5 鄱阳湖长江江豚的生存威胁}

根据农业农村部 (原农业部) 公开的 2008-2016 年长江中下游水域长江江豚死亡数据 (251 头) 分析, 意外死亡高发的时间是每年 11 月至次年 4 月. 其中大部分长江江豚死因不明,或者因为腐烂严重被当地渔 政部门掩埋. 从能够辨别的死因分析来看, 非法渔具 $(23.7 \%)$ 、螺旋桨 $(19.6 \%$, 无法分辨死前被击打还是死 后被击打)、疾病 ( $14.4 \%)$ 和饥饿 $(13.4 \%)$ 是主要原因.

鄱阳湖长江江豚种群结构的调查结果显示, 该种群具有较高的妊娠率和相对较短的生殖间隔, 自然繁 殖力很强. 然而自 2005 年以来种群数量仍然相对稳定 (种群数量未达环境容纳量), 说明非自然因素导致的 个体死亡可能是鄱阳湖长江江豚种群发展面临的主要问题 ${ }^{[18]}$. 近年来鄱阳湖人为活动加剧、鱼类资源快速 衰退及异常低水位的频繁出现, 给鄱阳湖长江江豚的生存带来严重挑战, 其中无序挖砂及非法渔业活动等 造成的栖息地丧失及质量下降、鱼类资源衰退和直接导致的伤亡等是长江江豚生存的主要威胁因素.

\section{1 鱼类资源衰退及非法渔业活动}

长江江豚是典型的机会型捕食者, 小型鱼类资源衰退是导致种群快速下降的主要原因之一 ${ }^{\left[{ }^{[37]}\right.}$. 鄱阳湖 长期过度捕捞及非法渔具的使用, 破坏了鱼类资源, 渔获物组成也日趋小型化, 低龄化, 渔获量严重下降, 食 物的短缺对长江江豚的长期生存造成威胁 ${ }^{[38]}$. 对鄱阳湖长江江豚食性研究的结果显示, 长江江豚食性的变 化主要由湖区鱼类组成的季节性变化引起, 半洄游型鱼类是长期的主要食物来源, 半洄游型鱼类的保护对 鄱阳湖长江江豚保护非常重要 ${ }^{[39]}$.

渔民作业时使用的有害和非法渔具渔法, 比如滚钩、迷魂阵, 甚至是毒鱼、炸鱼、电鱼等, 对豚类有直接 的杀伤作用, 常导致意外死伤 ${ }^{[1]}$. 在鄱阳湖开展的渔民调查结果显示, 在长江十年禁捕实施之前, 渔民普遍 大量使用非法渔具, 而且为了规避监管, 他们多是在夜间开展非法捕捞. 长江江豚具有晨昏捕食的特性, 在 夜间和清晨及傍晚时分捕食活跃, 这就导致非法捕捞活动与长江江豚捕食时空重叠. 尽管渔民没有主观伤 害长江江豚的意愿, 但由于误捕导致的伤亡不可避免. 因此, 解决鱼类资源持续下降和渔民生存之间的矛盾 是实现鄱阳湖水生生物多样性恢复和保护的关键 ${ }^{[40]}$. 自 2021 年开始, 在鄱阳湖全湖实施十年禁渔, 这将为 水生生物的保护和恢复提供重要的机遇 ${ }^{[13]}$, 也将较好地促进鄱阳湖长江江豚种群的保护.

\section{2 采砂}

2000 年以后, 长江干流禁止采砂, 鄱阳湖是长江中下游流域的重要采砂区, 多年来的超负荷采砂对湖区 
的生态环境造成了较大影响 ${ }^{[41]}$. 无序及过量的采砂作业导致长江江豚栖息地破坏,包括: 采砂严重破坏底 栖生物和鱼类栖息地、破坏河床底质及区域水体的理化性质 ${ }^{[42]}$ 、改变水文情势和增加水下噪声等 ${ }^{[43]}$, 导致 采砂区域渔业资源下降和栖息地丧失及质量下降, 影响长江江豚生存. 同时, 采砂和运砂船产生的水下噪声 可能会干扰长江江豚的声呐系统, 导致动物听觉系统受损, 甚至船舶的螺旋桨会直接击伤、击死动物. 此外, 由于采砂导致湖区河床下降, 枯水期湖区水位进一步降低, 水域面积缩小, 航运密度增加等, 进一步加剧了 人类活动与长江江豚接触的密度, 放大了各种人类活动的威胁 ${ }^{[18]}$.

\section{3 涉水工程建设}

涉水工程对长江江豚的首要影响可能是造成迁移的阻隔 ${ }^{[1]}$. 对鄱阳湖湖口水域的铜九铁路大桥火车通 过时不同桥墩处的水下噪声进行监测, 结果显示, 火车通行时噪声都只明显增加背景噪声的低中频成分 (2 $\mathrm{kHz}$ 以下), 而在较高频率 ( $10 \mathrm{kHz}$ 以上) 没有增加或者增加不明显. 桥墩处 (距离 $2 \mathrm{~m}$ ) 和窄孔径间 ( $40 \mathrm{~m}$ 墩 距) 的火车噪声在全频带高于背景噪声近 $30 \mathrm{~dB}(\mathrm{re} 1 \mu \mathrm{Pa})$, 这说明在窄孔径的铁路桥水域, 完全形成了一道 声音屏障. 宽孔径 (126 m 墩距) 的两桥墩间噪声较小 ${ }^{[44]}$.

此外,涉水施工过程中船舶、机械设备等各种作业以及运行后大型航行船舶的聚集和装卸将可能会对 生活在该水域的长江江豚产生一些影响,这些影响主要包括以下几个方面: 1) 水下噪声强度增加, 长江江豚 呈现逃避和长潜的行为 ${ }^{[45]}$. 连续的水下噪声可能会导致长江江豚声呐系统功能紊乱, 无法定位和巡航, 其 结果是被螺旋桨击伤或击毕. 而水下爆破施工等, 会产生高强度的水下噪声, 可能直接导致其死亡. 研究表 明, 湖口至南京之间江段, 接近 $30 \%$ 的白鰂豚是由于水下爆破和船舶撞击导致的直接损伤而死亡 ${ }^{[46]}$. 2) 水 利工程施工和营运期间, 由于江面被挤占, 单位面积水面船舶数量会增加, 甚至出现船舶聚集, 船舶产生的 噪声虽然不会导致豚类和其他水生动物死亡, 但是螺旋桨击伤和击毕的可能性不能排除. 3) 施工冲洗废水、 施工船舶和运输船舶污水以及施工人员的生活污水等, 或可能发生泄露的风险, 对周边水质产生影响, 间接 影响长江江豚的生存.

\section{4 航运交通}

被誉为 “黄金水道” 的长江航运业发展迅速, 长江水道各类航行船只急剧增加. 据统计, 长江下游机动船 只数量每 10 年翻一番, 近年来, 每天在长江上航行的船只近 7 万艘, 其密度是 5 年前的 3 倍. 特别是那些 $3000 \sim 30000(\mathrm{~kg} \cdot \mathrm{m}) / \mathrm{s}$ 的小型运输船, 占有比例大, 且其上行航线是沿 $4 \sim 8 \mathrm{~m}$ 水深的缓流行驶, 这驱使长江 干流江豚逐渐远离近岸适宜栖息水域, 更显著呈现围绕沙洲分布的特征 ${ }^{[47]}$. 长江干流不同江段水下噪声测 量结果表明, 除复新洲中部夹江的水下噪声声压级约 $130 \mathrm{~dB}($ re $1 \mu \mathrm{Pa})$ 外, 其余江段的水下噪声均为 $140 \sim$ $150 \mathrm{~dB}$, 会对长江江豚的分布造成显著影响 ${ }^{[48]}$.

鄱阳湖的航运主要集中在通江水道和赣江北支水域, 枯水期水面束窄后, 密集的航运对长江江豚的影 响不容忽视, 研究显示枯水期鄱阳湖长江江豚的目击率与货船密度呈现显著负相关关系 ${ }^{[30]}$.

\section{5 水体污染}

长江江豚生活在水中, 但是并不会直接饮用江水, 主要依靠食物来补充水分. 因此,一般意义上的水质 污染 (例如营养盐等), 并不会直接造成长江江豚伤害, 其主要的影响机制是导致长江江豚饵料资源的下降, 以及污染物通过食物链富集在长江江豚体内, 导致动物伤亡 ${ }^{[1]}$. 长江和鄱阳湖近岸水域部分金属元素含量 水平较高, 已受不同程度污染. 重金属的毒性通过联合或转化而加强, 可以通过食物链成千上万倍地富集放 大, 特别在鱼类、虾贝类富集程度更高, 直接影响鱼类乃至以鱼为食的长江江豚的健康和生长发育 ${ }^{\left[{ }^{[4]}\right.}$.

一些持久性污染物和重金属等, 亦可以通过皮肤接触和食物链等途径, 短期内在长江江豚身上大量富 集,造成急性伤亡. 1984 年在安庆江段望江水域发现一头十分瘦弱的长江江豚,死亡后其肌肉中二氯二苯基 三氯乙烷 (DDT) 和六六六农药残量分别达 $4.9 \times 10^{-6}$ 和 $15 \times 10^{-6} \mathrm{mg} / \mathrm{kg}$, 在海洋中生活的条纹原海豚 (Stenella coeruleoalba) 体内则分别只有 $0.03 \times 10^{-6} \sim 2.18 \times 10^{-6}$ 和 $0.003 \times 10^{-6} \sim 0.02 \times 10^{-6} \mathrm{mg} / \mathrm{kg}^{[50]} .2005$ 年, 在洞庭湖水 域,由于过量投放杀灭钉螺的药物引起近岸水体污染, 导致 5 头长江江豚因为永中毒死亡 ${ }^{[51]}$.

当前尚未有鄱阳湖长江江豚污染物的相关研究, 一项集合长江干流和洞庭湖及鄱阳湖的研究显示, 长 江江豚体内持久性污染物的含量较高, 其中 DDT 可能会对长江江豚的生存造成风险 ${ }^{[52]}$. 而对重金属的分析 发现长江江豚体内微量元素浓度在长江干流和两湖之间没有显著差异, 长江江豚组织中录和镉的含量高于 
其他小型鲸类, 对它们毒性的潜在风险需进一步关注 ${ }^{[53]}$.

\section{6 保护建议和未来研究方向}

\section{1 将鄱阳湖建成长江江豚国家级自然保护区}

2004 年 4 月, 经江西省人民政府批准,建立了鄱阳湖长江江豚省级自然保护区, 总面积 $6800 \mathrm{hm}^{2}$, 包括 老爷庙小区 $\left(4900 \mathrm{hm}^{2}\right)$ 和龙口小区 $\left(1900 \mathrm{hm}^{2}\right)$, 核心区面积 $2700 \mathrm{hm}^{2}$. 连续的种群监测显示, 鄱阳湖是长江 江豚分布密度最高的水域, 不同水位时期长江江豚在全湖都呈现高密度分布, 当前的保护区面积较小, 无法 有效覆盖全部高密度分布区 ${ }^{[21]}$. 鉴于鄱阳湖长江江豚保护的重要性, 建议整合当前的各类保护地, 将鄱阳 湖建设成为长江江豚国家级自然保护区.

\section{2 管控通江水道人类活动, 促进江湖迁移行为恢复}

研究显示, 维持洞庭湖和鄱阳湖长江江豚种群与长江干流种群的交流会显著延缓长江江豚种群的平均 灭绝时间 ${ }^{[11]}$. 低水位时期,都昌老爷庙水域是整个湖区最大和最连续的适宜栖息地. 此外,在鄱阳湖的通江 水道上,尤其是蛤蟆石至湖口水域, 是鄱阳湖低水位时期长江江豚适宜的栖息地 ${ }^{[21]}$. 但是, 连续的监测显 示, 在这些水域长江江豚分布密度不高, 江湖移动的行为和规模都显著缩小, 提示长江江豚在这些水域的分 布受到人类活动的影响. 建议未来需要更关注低水位时期通江水道人类活动的管控, 恢复长江江豚分布, 甚 至可以促进其江湖移动.

\section{3 切实加强鄱阳湖水域非法人类活动的管理}

曹文宣院士指出: “鄱阳湖的长江江豚保护工作最重要的问题不是挖沙, 不是航运、不是非法捕捞, 不是 水污染, 也更加不是低枯水位！对上述这些人类活动的有效管理才是最关键的问题!” 通过对鄱阳湖捕获长 江江豚种群的血液生理生化分析,结果也显示其面临栖息地恶化和外部的环境压力 ${ }^{[54-55]}$. 在长江十年禁渔 的有利条件下, 切实加强鄱阳湖水域非法人类活动的管理, 彻底清除非法捕捞, 科学规划采砂区域及采砂 量, 管控航运船舶等, 可显著提升长江江豚的保护效果. 另外, 逐步取缔现有的围堰和矮围, 恢复湖区与碟形 湖之间的自由水文连通,或可有效促进鄱阳湖水生生境的保护和恢复.

\section{4 建立鄱阳湖长江江豚研究保护中心}

多年来, 鄱阳湖长江江豚的研究工作主要由中国科学院水生生物研究所开展. 近五年, 江西省内的科研 院所开始参与长江江豚种群和栖息地监测. 为了提高鄱阳湖长江江豚等水生生物的保护, 2021 年 1 月江西 省成立了鄱阳湖水生生物保护救助中心, 主要承担全省水生生物保护、救护、利用等工作. 我们建议该中心 也同时加强对鄱阳湖长江江豚的研究和监测, 例如采用长航时无人机和实时水下被动声学监测等手段, 建 立鄱阳湖长江江豚种群监测体系. 此外, 该中心还应在靠近鄱阳湖主湖区水域建设长江江豚救护基地, 实施 鄱阳湖长江江豚的救护工作.

\section{5 未来研究建议}

建议未来开展以下研究: 1) 翻阳湖长江江豚种群动态监测; 2) 湖口水域长江江豚江湖迁移行为监测 ; 3 ) 鄱阳湖长江江豚在湖区与支流间移动规律; 4) 采砂遗留沙坑水域栖息地质量评价; 5 ) 鄱阳湖长江江豚遗传 多样性评估;6)航运对鄱阳湖长江江豚的影响;7) 长江江豚的污染物暴露风险;8)气候变化对鄱阳湖长江 江豚的威胁.

\section{7 参考文献}

[ 1 ] Wang D. Population status, threats and conservation of the Yangtze finless porpoise. Chinese Science Bulletin, 2009,54 (19) : 3473-3484. DOI: 10.1007/s11434-009-0522-7.

[ 2 ] Wang PL. Taxonomy of finless porpoise of China. Journal of Fishery Sciences, 1992, (6): 10-14. [王丕烈. 中国江豚的 分类. 水产科学, 1992, (6): 10-14.]

[ 3 ] Gao AL, Zhou KY. Geographical variation of external measurements and three subspecies of Neophocaena phocaenoides in Chinese waters. Acta Theriologica Sinica, 1995, 15(2) : 81-92. DOI: 10.16829/j.slxb.1995.02.001. [高安利, 周开亚. 中国水域江豚外形的地理变异和江豚的三亚种. 兽类学报, 1995, 15(2): 81-92.]

[ 4 ] Jefferson TA, Wang JY. Revision of the taxonomy of finless porpoises (genus Neophocaena): The existence of two species. 
Journal of Marine Animals and Their Ecology, 2011, 4(1): 3-16.

[ 5 ] Zhou XM, Guang XM, Sun D et al. Population genomics of finless porpoises reveal an incipient cetacean species adapted to freshwater. Nature Communications, 2018, 9: 1276. DOI: 10.1038/s41467-018-03722-x.

[ 6 ] Committee on Taxonomy. List of marine mammal species and subspecies. Society for Marine Mammalogy. http://www. marinemammalscience.org. Accessed 10 May 2020.

[ 7 ] Wang D, Turvey ST, Zhao X et al. Neophocaena asiaeorientalis ssp. asiaeorientalis. The IUCN red list of threatened species, 2013.

[ 8 ] Zhang XF, Liu RJ, Zhao QZ et al. The population of finless porpoise in the middle and lower reaches of Yangtze River. Acta Theriologica Sinica , 1993 , 13(4) : 260-270. DOI: 10.16829/j.slxb.1993.04.005. [张先锋, 刘仁俊, 赵庆中等. 长 江中下游江豚种群现状评价. 兽类学报, 1993, 13(4) : 260-270.]

[ 9 ] Zhao XJ, Barlow J, Taylor BL et al. Abundance and conservation status of the Yangtze finless porpoise in the Yangtze River, China. Biological Conservation, 2008, 141(12) : 3006-3018. DOI: 10.1016/j.biocon.2008.09.005.

[10] Mei ZG, Zhang XQ, Huang SL et al. The Yangtze finless porpoise: On an accelerating path to extinction? Biological Conservation, 2014, 172: 117-123. DOI: 10.1016/j.biocon.2014.02.033.

[11] Huang SL, Mei ZG, Hao YJ et al. Saving the Yangtze finless porpoise: Time is rapidly running out. Biological Conservation, 2017, 210: 40-46. DOI: 10.1016/j.biocon.2016.05.021.

[12] Huang J, Mei ZG, Chen M et al. Population survey showing hope for population recovery of the critically endangered Yangtze finless porpoise. Biological Conservation, 2020, 241 : 108315. DOI: 10.1016/j.biocon.2019.108315.

[13] Mei ZG, Cheng PL, Wang KX et al. A first step for the Yangtze. Science, 2020, 367(6484) : 1314. DOI: 10.1126/science.abb5537.

[14] Studies on Lake Poyang Editorial Committee. Studies on Lake Poyang. Shanghai: Shanghai Science and Technology Press, 1988. [《鄱阳湖研究》编委会. 鄱阳湖研究. 上海: 上海科学技术出版社, 1988.]

[15] Min Q. Brief introduction of Lake Poyang. J Lake Sci, 1993, 5(1) : 96-97. [闵骞. 鄱阳湖简介. 湖泊科学, 1993, 5 (1) : 96-97.]

[16] Xiao W, Zhang XF. A preliminary study on the population size of Yangtze finless propoise in Poyang Lake, Jiangxi. Chinese Biodiversity, 2000, 8(1): 106-111. [肖文, 张先锋. 截线抽样法用于鄱阳湖江豚种群数量研究初报. 生物多样 性, 2000, 8(1): 106-111.]

[17] Zhao XJ. Study on the method of cetacean population survey in river system and its application [Dissertation]. Wuhan: Institute of Hydrobiology, Chinese Academy of Sciences, 2009. [ 赵修江. 河流系统鲸豚类种群数量调查方法探索及其 应用研究 [学位论文]. 武汉: 中国科学院水生生物研究所, 2009.]

[18] Mei ZG. Study on population dynamics and endangered mechanism of Yangtze finless porpoise [Dissertation]. Wuhan: Institute of Hydrobiology, Chinese Academy of Sciences, 2013. [梅志刚. 长江江豚种群变动趋势及濒危机制的研究 [学 位论文]. 武汉: 中国科学院水生生物研究所, 2013.]

[19] Dong LJ, Wang D, Wang KX et al. Yangtze finless porpoises along the main channel of Poyang Lake, China: Implications for conservation. Marine Mammal Science, 2015, 31(2) : 612-628. DOI: 10.1111/mms.12181.

[20] Yang J, Xiao W, Kuang XA et al. Study on ecology of Baiji and Yangtze finless porpoise in Dongting Lake and Poyang Lake. Resources and Environment in the Yangtze Basin, 2000, (4): 444-450. [杨健, 肖文, 匡新安等. 洞庭湖、鄱阳湖 白暨豚和长江江豚的生态学研究. 长江流域资源与环境, 2000, (4) : 444-450.]

[21] Liu X. Study on the movement and influencing factors of Yangtze finless porpoise in the main lake area and tributaries of Poyang Lake [Dissertation]. Wuhan: Institute of Hydrobiology, Chinese Academy of Sciences, 2020. [刘馨. 鄱阳湖主 湖区及主要支流长江江豚移动规律与影响因素研究 [学位论文]. 武汉: 中国科学水生生物研究所, 2020.]

[22] Zhao XJ, Wang D. Abundance and distribution of Yangtze finless porpoise in Balijiang section of the Yangtze River. Resources and Environment in the Yangtze Basin, 2011, 20(12): 1432-1439. [ 赵修江, 王丁. 长江八里江江段的江豚种 群数量与分布. 长江流域资源与环境, 2011, 20(12): 1432-1439.]

[23] Wei Z, Zhang XF, Wang KX et al. Habitat use and preliminary evaluation of the habitat status of the Yangtze finless porpoise (Neophocaena phocaenoides asiaeorientalis) in the Balijiang section of the Yangtze River, China. Acta Zoologica Sini$c a, 2003,49(2): 163-170$. [魏卓, 张先锋, 王克雄等. 长江江豚对八里江江段的利用及其栖息地现状的初步评 价. 动物学报, 2003, 49(2): 163-170.] 
[24] Kimura S, Akamatsu T, Li SH et al. Seasonal changes in the local distribution of Yangtze finless porpoises related to fish presence. Marine Mammal Science, 2012, 28(2) : 308-324. DOI: 10.1111/j.1748-7692.2011.00490.x.

[25] Yu DP, Wang J, Yang G et al. Primary analysis on habitat selection of Yangtze finless porpoise in spring in the section between Hukou and Digang. Acta Theriologica Sinica, 2005, 25(3) : 302-306. DOI: 10.16829/j.slxb.2005.03.016. [于道 平, 王江, 杨光等. 长江湖口至荻港段江豚春季对生境选择的初步分析. 兽类学报, 2005, 25(3) : 302-306.]

[26] Wang ZT, Akamatsu T, Wang KX et al. The diel rhythms of biosonar behavior in the Yangtze finless porpoise (Neophocaena asiaeorientalis asiaeorientalis) in the port of the Yangtze River: The correlation between prey availability and boat traffic. PLoS One, 2014, 9(5) : e97907. DOI: 10.1371/journal.pone.0097907.

[27] Wang ZT, Akamatsu T, Mei ZG et al. Frequent and prolonged nocturnal occupation of port areas by Yangtze finless porpoises (Neophocaena asiaeorientalis) : Forced choice for feeding? Integrative Zoology, 2015, 10(1) : 122-132. DOI: 10. $1111 / 1749-4877.12102$.

[28 ] Chen MM, Liu ZG, Huang J et al. Effects of artificial riverbanks on distribution of the Yangtze finless porpoise in the Anqing section of the Yangtze River main stem. Acta Ecologica Sinica, 2018, 38(3) : 945-952. [ 陈敏敏, 刘志刚, 黄杰等. 固化河岸对长江江豚栖息活动的影响. 生态学报, 2018, 38(3):945-952.]

[29] Zhang JX, Chen M, Han Y et al. River bank habitat assessment of the Yangtze finless porpoise in the main stem of middlelower Yangtze River. Acta Hydrobiologica Sinica, 2019, 43(S1) : 56-61. [章晋秀, 陈惁, 韩神等. 长江中下游干流江 豚岸线栖息地质量评估. 水生生物学报, 2019, 43(S1): 56-61.]

[30] Huang J. Study on present situation of population and habitat selection mechanism of the Yangtze finless porpoise [Dissertation]. Wuhan: Institute of Hydrobiology, Chinese Academy of Sciences, 2019. [黄杰. 长江江豚种群现状及栖息地选 择机制的研究 [ 学位论文]. 武汉: 中国科学院水生生物研究所, 2019.]

[31] Hua YY, Zhang J, Zhang X et al. Research on the status quo and endangering factors of Baiji, Lipotes vexillifer, and the strategy for its protection. Pesources and Enuironment in the Yangtze Valley, 1995, 4(1): 45-51. [华元渝, 张建, 章贤 等. 白暨豚种群现状、致危因素及保护策略的研究. 长江流域资源与环境, 1995, 4(1): 45-51.]

[32] Chen MM, Zheng Y, Hao YJ et al. Parentage-based group composition and dispersal pattern studies of the Yangtze finless porpoise population in Poyang Lake. International Journal of Molecular Sciences, 2016, 17 (8) : 1268. DOI: 10.3390/ ijms17081268.

[33] Wei Z, Wang D, Zhang XF et al. Population size, behavior, movement pattern and protection of Yangtze finless porpoise at Balijiang section of the Yangtze River. Resources and Environment in the Yangtze Basin, 2002, 11(5) : 427-432. [魏 卓, 王丁, 张先锋等. 长江八里江江段江豚种群数量、行为及其活动规律与保护. 长江流域资源与环境, 2002,11 ( 5) : 427-432.]

[34] Kimura S, Akamatsu T, Wang KX et al. Comparison of stationary acoustic monitoring and visual observation of finless porpoises. The Journal of the Acoustical Society of America, 2009, 125(1) : 547-553. DOI: 10.1121/1.3021302.

[35] Dong SY. Studies on distribution and movement pattern of Yangtze finless porpoises (Neophocaena phocaenoides asiaeorientalis) in Hukou area by acoustic data loggers [Dissertation]. Wuhan: Institute of Hydrobiology, Chinese Academy of Sciences, 2009. [ 董首悦. 采用声学方法研究湖口水域长江江豚的分布及其活动规律 [ 学位论文]. 武汉: 中国科学院 水生生物研究所, 2009.]

[36] Chen MM. Studies on the population history, genetic diversity and population genetic structure of the Yangtze finless porpoise (Neophocaena asiaeorientalis asiaeorientalis) [Dissertation]. Wuhan: Institute of Hydrobiology, Chinese Academy of Sciences, 2015. [ 陈敏敏. 长江江豚种群历史、遗传多样性和种群遗传结构研究 [ 学位论文]. 武汉: 中国科学院水 生生物研究所, 2015.]

[37] Yang JW, Wan XL, Zeng XY et al. A preliminary study on diet of the Yangtze finless porpoise using next-generation sequencing techniques. Marine Mammal Science, 2019, 35(4) : 1579-1586. DOI: 10.1111/mms.12585.

[38] Fu PF, Wang S, He G. A preliminary analysis of the protection of finless porpoise in Poyang Lake of Jiangxi Province. Jiangxi Fishery Sciences and Technology, 2017, (3): 44-46. [ 傅培峰, 王生, 贺刚. 浅谈江西省鄱阳湖长江江豚保护. 江西水产科技, 2017, (3) : 44-46.]

[39] Yang JW, Wang K, Mei ZG et al. Temporal variation in the diet of Yangtze finless porpoise calls for conservation of semimigratory fish. Freshwater Biology, 2021, 66(5) : 992-1001. DOI: 10.1111/fwb.13692.

[40] Mei ZG, Han Y, Dong LJ et al. The impact of fisheries management practices on the survival of the Yangtze finless por- 
poise in China. Aquatic Conservation: Marine and Freshwater Ecosystems, 2019, 29(4): 639-646. DOI: 10. 1002/ aqc.3078.

[41] Zhang ZL, Huang LZ. Influence of quarrying in Poyang Lake on the ecological environment. Jiangxi Hydraulic Science \& Technology, 2008, 34(1) : 7-10. [张子林, 黄立章. 浅析鄱阳湖采砂对生态环境的影响. 江西水利科技, 2008, 34 (1): 7-10.]

[42] Meng XL, Jiang XM, Li ZF et al. Responses of macroinvertebrates and local environment to short-term commercial sand dredging practices in a flood-plain lake. Science of the Total Environment, 2018, 631/632: 1350-1359. DOI: 10.1016/j. scitotenv.2018.03.086.

[43] Wang ZT. Study on the impacts of sand mining activities in Dongting Lake on Yangtze finless porpoise [Dissertation]. Wuhan: Institute of Hydrobiology, Chinese Academy of Science, 2015. [王振太. 洞庭湖采砂活动对长江江豚的影响研究 [学位论文]. 武汉: 中国科学院水生生物研究所, 2015.]

[44] Shi WJ. Impact assessment of underwater noise caused by aquatic construction and traffic on the Yangtze finless porpoise. [Dissertation]. Wuhan: Institute of Hydrobiology, Chinese Academy of Science, 2013. [时文静. 涉水施工及水上交通 所致水下噪声对长江江豚影响评价 [学位论文]. 武汉: 中国科学水生生物研究所, 2013.]

[45] Wang KX, Wang D. Analysis of impact of waterway adjustment activities on Yangtze finless porpoise and mitigation measures. Environmental Impact Assessment, 2015, 37(3) : 13-17. DOI: 10.14068/j.ceia.2015.03.004. [王克雄, 王丁. 航道 整治工程对长江江豚影响及缓解措施分析. 环境影响评价, 2015, 37(3): 13-17.]

[46] Turvey ST, Pitman RL, Taylor BL et al. First human-caused extinction of a cetacean species?. Biology Letters, 2007, 3 (5) : 537-540. DOI: $10.1098 / \mathrm{rsbl} .2007 .0292$.

[47] Mei ZG, Han Y, Turvey ST et al. Mitigating the effect of shipping on freshwater cetaceans: The case study of the Yangtze finless porpoise. Biological Conservation, 2021, 257: 109132. DOI: 10.1016/j.biocon.2021.109132.

[48] Wang ZT, Akamatsu T, Duan PX et al. Underwater noise pollution in China's Yangtze River critically endangers Yangtze finless porpoises (Neophocaena asiaeorientalis asiaeorientalis). Environmental Pollution, 2020, 262: 114310. DOI: 10. 1016/j.envpol.2020.114310.

[49] Chen JZ, Zai JH, Hu GD. Effects of chromium on non- specific immunity of Cyprinus carpio Linn. Journal of Zhejiang Ocean University: Natural Science, 2002, (1) : 16-18, 32. [陈家长, 睢建宏, 胡庚东. 铬对鲤鱼非特异性免疫功能的 影响. 浙江海洋学院学报: 自然科学版, 2002, (1): 16-18, 32.]

[50] Yang LS, Yu DW, Lu PH. Studies on the levels of some metals and organichlorine compounds in Lipotes vexillifer and Neophocaena phocaenoides. Acta Theriologica Sinica, 1988, 8(2) : 122-127. DOI: 10.16829/j.slxb.1988.02.007. [杨利寿, 余多慰, 陆佩洪. 白暨豚和江豚体内几种金属元素和有机氯的研究. 兽类学报, 1988, 8(2): 122-127.]

[51] Dong WW, Xu Y, Wang D et al. Mercury concentrations in Yangtze finless porpoises (Neophocaena phocaenoides asiaeorientalis) from Eastern Dongting Lake, China. Fresenius Environmental Bulletin, 2006, 15(5) : 441-447.

[52] Zhang K, Qian ZY, Ruan YF et al. First evaluation of legacy persistent organic pollutant contamination status of stranded Yangtze finless porpoises along the Yangtze River Basin, China. Science of the Total Environment, 2020, 710: 136446. DOI: $10.1016 /$ j.scitotenv.2019.136446.

[53] Xiong X, Qian ZY, Mei ZG et al. Trace elements accumulation in the Yangtze finless porpoise (Neophocaena asiaeorientalis asiaeorientalis) - A threat to the endangered freshwater cetacean. Science of the Total Environment, 2019, 686: 797 804. DOI: $10.1016 /$ j.scitotenv.2019.06.031.

[54] Nabi G, Robeck TR, Hao YJ et al. Circulating concentrations of thyroid hormones and cortisol in wild and semi-natural Yangtze finless porpoise (Neophocaena asiaeorientalis). Conservation Physiology, 2021, 9(1). DOI: 10.1093/conphys/ coab034.

[55] Nabi G, Hao YJ, Robeck TR et al. Physiological consequences of biologic state and habitat dynamics on the critically endangered Yangtze finless porpoises (Neophocaena asiaeorientalis ssp. asiaeorientalis) dwelling in the wild and semi-natural environment. Conservation Physiology, 2018, 6(1) : coy072. DOI: 10.1093/conphys/coy072. 